\title{
La imagen te pide: marginalia de comunicación política
}

\author{
María Gabriela Macagno \\ Facultad de Arquitectura, Diseño y Urbanismo \\ Facultad de Humanidades y Ciencias \\ Universidad Nacional del Litoral \\ gabimacagno@gmail.com
}

\author{
Sergio Peralta \\ Universidad Nacional del Litoral \\ tesisyantitesis@gmail.com
}

\section{Resumen}

En este artículo se propone una trama conceptual para analizar el material audiovisual generado para informar el nuevo Sistema de Boleta Única para las elecciones en la provincia de Santa Fe en el año 20II. Se reflexiona sobre la construcción de saberes en la comunicación masiva, considerando aspectos narrativos, cognitivos e iconopoiéticos. Para hacer comunicación visual, las culturas ofrecen «archivos de imágenes» y los diseñadores toman decisiones estratégicas.

\section{Abstract}

This article proposes a conceptual framework for the analysis of the audiovisual material which was produced to inform the public about the new ballot system for 20II Santa Fe provincial elections. We reflect on the construction of knowledge in mass communication, considering narrative, cognitive and
Palabras clave:

comunicación inferencial, eficacia performativa, imagen, Sistema Electoral de Boleta Única.

\section{Key words:}

Inferential communication, performative efficacy, image, Voter-marked Paper Ballot System. 
iconic-poietic aspects. To achieve visual communication, cultures offer «image files» and designers make strategic decisions.

\section{Preliminares}

El Sistema de Boleta Única (sBu) es un nuevo sistema electoral implementado en la Provincia de Santa Fe para las elecciones provinciales del año 20II. Como novedad que potenciaría la democracia, fue demandado, a nivel nacional, por diversos agentes políticos desde, por lo menos, el año 200I, y reapareció como demanda en coyunturas electorales enjuiciadas como viciadas. El Centro de Implementación de Políticas Públicas para la Equidad y el Crecimiento (CIPPEC) comenzó a teorizar el Proyecto Boleta Única en mayo de 2009, generando sucesivos documentos en los cuales, entre otros tópicos, se lo relaciona con las democracias avanzadas y como mejorador de la reforma política debatida ese mismo año (Mustapic \& Straface, 2009). Asimismo, firmados por el CIPPEC, se encuentran documentos digitales utilizados para difundir la propuesta por medio de talleres para periodistas y notas de opinión poselectorales en el diario El Litoral, valorando los aspectos positivos del nuevo sistema electoral (cf. los repositorios documentales citados al final de este artículo).

Una parte importante de las campañas de comunicación se realizó mediante spot audiovisuales de diversa factura en cuanto a «lenguajes» visuales, de los cuales seleccionamos tres para nuestro análisis: el spot oficial rubricado por el Gobierno de Santa Fe (animación con pictogramas) y los spots de los candidatos Pablo Javkin (ilustración animada) y Agustín Rossi (fílmico). Este trabajo pretende generar una trama conceptual, mediante un proceder emergente (Santander, 20II), para analizar estos spots realizados para difundir el SBU, por televisión e Internet. La organización de la indagación sobre los materiales continúa la propuesta de Fairclough (1995): analizar los textos (audiovisuales, para el caso) como parte de prácticas discursivas inscriptas en prácticas socioculturales. El interrogante implícito que orienta la investigación apunta a indagar los modos en que se construyen saberes utilizando imágenes, retomando aquí la propuesta analítica de la Semiótica Visual de Magariños de Morentín (2008). Además de esta importante referencia, se retoman consideraciones metodológicas de la semiótica del texto fílmico (Carmona, 1993) y conceptos de la morfología del film (Bordwell, 1985; Oubiña, 2008), junto con categorías analíticas provenientes de los Estudios de Comunicación, en especial, de la «com- 